Original Research Article

\title{
A prospective study on the use of anesthetic agents in modern surgical practice at a tertiary care hospital, Karnataka, India
}

\author{
Deeptangshu Ganguly ${ }^{1}$, Dharani D. Ranganath ${ }^{2 *}$, Manohar Herle ${ }^{3}$, \\ Rajasekhar C. H. ${ }^{4}$, Kokila B. Nagaraj ${ }^{3}$
}

${ }^{1}$ Department Of Pharmacology, IQ City Medical College, Durgapur, Kolkata, West Bengal, India

${ }^{2}$ Department Of Pharmacology, Shimoga Institute of Medical Sciences, Shimoga, Karnataka, India

${ }^{3}$ Department Of Pharmacology, KVG Medical College and Hospital, Sullia, (D.K),

Karnataka, India

${ }^{4}$ Department of Pharmacology, MM Medical College, Manipal, Karnataka, India

Received: 25 May 2017

Accepted: 19 June 2017

*Correspondence to: Dr. Dharani D. Ranganath, Email: dharanidevangi2707 @gmail.com

Copyright: (C) the author(s), publisher and licensee Medip Academy. This is an openaccess article distributed under the terms of the Creative Commons Attribution NonCommercial License, which permits unrestricted noncommercial use, distribution, and reproduction in any medium, provided the original work is properly cited.

\begin{abstract}
Background: The choice of local anesthetic is based on potency of the agent, onset and duration of anesthesia, and side effects of the drug Objectives of the study were, the study proposes to analysis the pattern, trend, rationality and frequency of use of anesthetic agents in modern surgical procedures.

Methods: The study records relevant data obtained from surgical case records of patients from department of General surgery, Obstetrics and Gynecology and Orthopedics during the period December 2014 to May 2015 including first one month of pilot study, at KVGMC, Sullia (D.K), Karnataka.

Results: A total of 744 cases were collected and screened according to inclusion and exclusion criteria and finally 348 cases were recorded and critically analysed. Sub-arachnoid block is the most common type of anesthetic procedure $(75.28 \%)$ performed by the anesthetists. Of 348 cases undergoing anesthesia using local anesthetic agents, 228 cases required only a single agent and 120 cases required a combination anesthetic agents. 206 underwent subarachnoid block, 16 epidural block (EPID) and only 2 brachial block. The most commonly used agent for maintainence of general anesthesia is Isoflurane $(68 \%)$ followed by Halothane $(32 \%)$ and the combination of skeletal muscle relaxants were Succinylcholine with either Atracurium (39.8\%) or Vecuronium $(37.16 \%)$. Analgesics were the most commonly used adjuvants followed by ondansetron.

Conclusions: The study showed that the most common anesthetic procedure performed using local anesthetic agents is SA/SAB block and the most common agent used is bupivacaine which was frequently employed at the dose range of 3-4 ml. There was significant association found between the no. of anesthetic agents used and the type of anesthetic procedure performed and also between the concerned department and the type of anesthetic procedure performed. Thus, the rationality in the usage of relevant anesthetic agents with appropriate adjuvants is evident.
\end{abstract}

Keywords: General anesthetics, Local anesthetics, Rational drug use

\section{INTRODUCTION}

Anaesthesia is reversible loss of sensation with or without loss of consciousness. The components of the anesthetic state include, amnesia, analgesia, unconsciousness, immobility in response to any noxious stimulation and attenuation of autonomic responses to noxious stimulation. The drugs causing anesthesia are called anesthetic agents. Anaesthetic agents are of two typesgeneral anaesthetics and local anaesthetics. Local anaesthesia is a process where local anesthetics can act on any part of nervous system and on every type of nerve 
fiber, reversibly blocking the action potentials responsible for nerve conduction where a small area of the body is anaesthetized with analgesia, loss of reflexes and skeletal muscle relaxation without loss of consciousness. ${ }^{1,2}$

The choice of local anesthetic is based on potency of the agent, onset and duration of anesthesia, and side effects of the drug. Mainly two groups of local anesthetics are used in spinal anesthesia - esters (procaine, tetracaine) and amides (bupivacaine, lidocaine) which are characterized by the bond that connects the aromatic portion and the intermediate chain. Dose, Metabolism, lipid solubility, protein binding, and $\mathrm{pKa}$ are important factors for determining activity of local anesthetics. ${ }^{3-5}$

Spinal anesthesia also known as subarachnoid block is a form of regional anaesthesia, which involves injection of a local anaesthetic agent into the subarachnoid cerebrospinal fluid space. The injection is usually made in the lumbar region at the L2-L3 or L3-L4 space. Spinal anaesthesia has the advantage of simplicity, rapid onset of action, low failure rate, minimum drug dose, and excellent muscle relaxation, which makes it the technique of choice for Surgeries below the umbilicus such as genitourinary surgery, hernial repair procedures or surgeries performed on the lower extremities (lower limbs) and Caesarian Sections.

Bupivacaine, Lidocaine, tetracaine, are the local anesthetic agents most commonly used for spinal anesthesia. Lidocaine is primarily useful for surgical procedures lasting less than one hour as it has shorter duration of action. Tetracaine and bupivacaine are used for procedures lasting for 2 to 5 hours. Vasoconstrictors can prolong the duration of spinal anesthesia of all three agents. In general, the local anesthetic agents that are currently available for spinal anesthesia provide significant versatility. By carefully considering the planned surgical procedure, the surgeon's requirements, and the patient's characteristics (e.g., age, height, gravidity), and by understanding the factors that influence spinal anesthesia, the anesthesiologist can select a local anesthetic agent that will assure adequate and satisfying spinal anesthesia. ${ }^{8}$

Bupivacaine is a local anaesthetic that stabilises the neuronal membrane and prevents the initiation and transmission of nerve impulses. This drug is very potent and has a rapid onset of anaesthesia with prolonged duration of action. Ropivacaine acts in the same manner as bupivacaine with exception that ropivacaine has both anaesthetic and analgesic effects. At higher doses, it produces surgical anaesthesia with motor block, while at lower doses it produces a sensory block, including analgesia, with little motor block. It is also less cardiotoxic than bupivacaine. ${ }^{9,10}$

Local anaesthetics are generally safe if used in recommended doses. However, most complications are related to the techniques, resulting in systemic toxicity, or to the effects of the block, rather than to the drugs used. Some examples of the complications of regional anaesthesia are-pain, post-dural puncture headache, hypotension and bradycardia, direct nerve damage, hypothermia, aseptic meningitis, spinal infections, spinal cord damage and urinary retention whereas that of local anesthesia are pain, bleeding, infection, necrosis and nerve injury. ${ }^{11-13}$

The selection of anaesthetics and their administration to produce anaesthesia is based on their pharmacokinetic properties and on the secondary effects of various drugs. Choice of anaesthetic agent is one of the multitude factors that would be significantly more important than anaesthetic technique as determinants of outcome after any surgery. The present study is based on the choice of anesthetic agent to be used, by considering the type of surgical procedure to be performed, patient's age, physiological condition of the patient like pregnancy, associated medical co-morbid conditions and medications used.

\section{METHODS}

The Data was collected from the Operation theatre records of General surgery, Obstetrics and Gynecologyand Orthopedics departments and was recorded in a specially designed proforma.

\section{Data collection}

A prospective, non-interventional, observational medical audit- study was undertaken during the period December 2014 to May 2015 including first one month of pilot study. The investigator met and sought help of operation theatre staffs, Head of the Department, faculty members and Post graduates of the department of Anesthesia, General surgery, Obstetrics and Gynecology and Orthopedics departments with regard to the conduct of study.

\section{The pilot study}

In order to gain familiarity with the topic and data collection, a pilot study was conducted over a period of one month.

Accordingly a special proforma was designed and data were obtained from Operation theatre case records of patients undergoing operative procedures under the departments of general surgery, Obstetrics and gynaecology and orthopaedic surgery, KVG Medical College Hospital, Sullia (D.K) Karnataka.

Subsequently, a few modifications were made in the said Performa as per requirements for the current study.

Thus, a specially designed proforma was used for data collection, under the following headings. 
1. Demographic data: Name, age, address, Inpatient (IP) number, date of admission/surgery of patients.

2. Medical history: Diagnosis / Indication for the surgery

3. Data pertaining to Surgery: Type of surgical procedure performed, the type of anaesthetic techniques employed, the choice of anesthetic agent/agents used with their respective dose and frequency and whether any other adjuvant drugs used concomitantly.

4. Data pertaining to complications of anaesthesia, if any.

\section{Inclusion criteria}

Patients undergoing major surgical procedures at above mentioned departmental operation theatres of K.V.G medical college hospital, Sullia (D.K).

\section{Exclusion criteria}

-Patients undergoing surgical procedures under infiltration block anesthesia and diagnostic procedures are excluded.

There was no need of follow up of patients.

\section{Statistical analysis}

The data thus obtained were subjected to statistical analysis. Descriptive statistical analysis was done using Microsoft office excel 2013 and qualitative analysis of data was performed using Fischer's exact test by SPSS software version 19 .

\section{RESULTS}

The results of my study are described in two parts:

- Results of local anesthetic agents

- Results of general anesthetic agents

\section{Results of local anesthetic agents}

First we depict the results of use of local anaesthetic agents.

A total of 744 cases were collected and screened according to inclusion and exclusion criteria and finally 348 cases were recorded and critically analysed.

The mean age of patients undergoing various surgeries using local anaesthetic agents is $42.98 \pm 1.25$.

The female patients $(54 \%)$ are more than male patients $(46 \%)$ undergoing various surgeries using local anaesthetic agents.

Figure 1 shows the Percentage of operative procedures performed under regional anaesthesia and Conduction block using local anaesthetic agents. Obstetrics and Gynaecology (OBG) department leads the group (35\%) followed by General Surgery (SURG) (33\%) and Orthopaedics (ORTHO) (32\%) though the distribution is almost uniform.

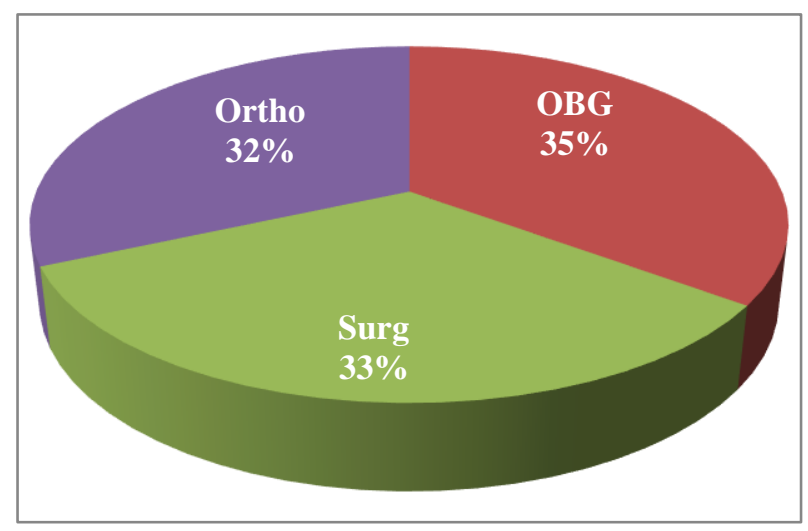

Figure 1: Percentage of cases according to departments.

The mean no. of anesthetic agents used for the operative procedures performed by the respective departments (OBG, SURG and ORTHO) is same 1.26 \pm 0.03 .

The frequency of types of anaesthetic procedures performed is depicted in Figure 2. It shows that Subarachnoid block (SAB) is the most common type of anesthetic procedure $(75.28 \%)$ performed by the anesthetists of K.V.G.M.C.H, sullia.

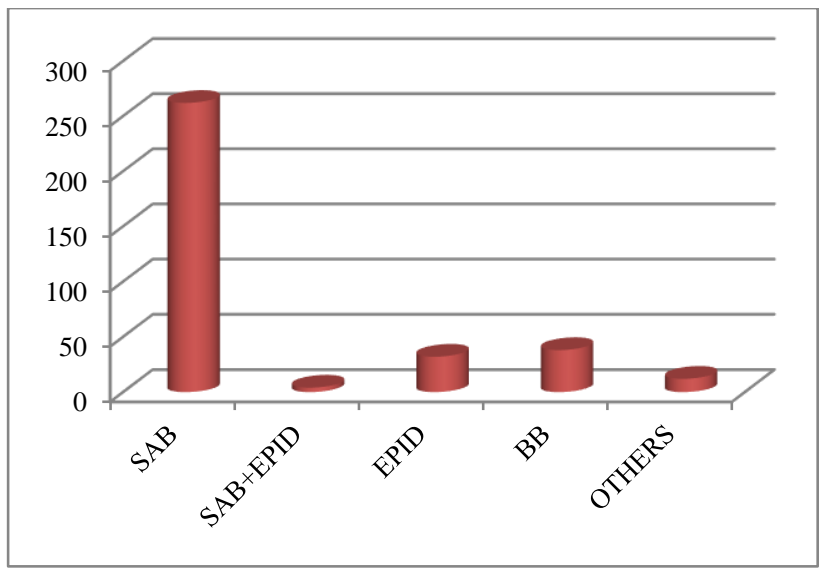

$\mathrm{SAB}=$ Sub-Arachnoid block

EPID=Epidural block

$\mathrm{BB}=$ Brachial block

Figure 2: Types of anesthetic procedures performed.

Figure 3 shows percentage of choice of anesthetic agent. Among 348 cases, 206 cases use bupivacaine (B) as a single agent for performing regional anesthesia and conduction block $(59 \%)$ followed by combination of bupivacaine (B) and lignocaine (L) (26\%). Ropivacaine (R) and Levobupivacaine (LB) as single or combination were very seldomly used. 


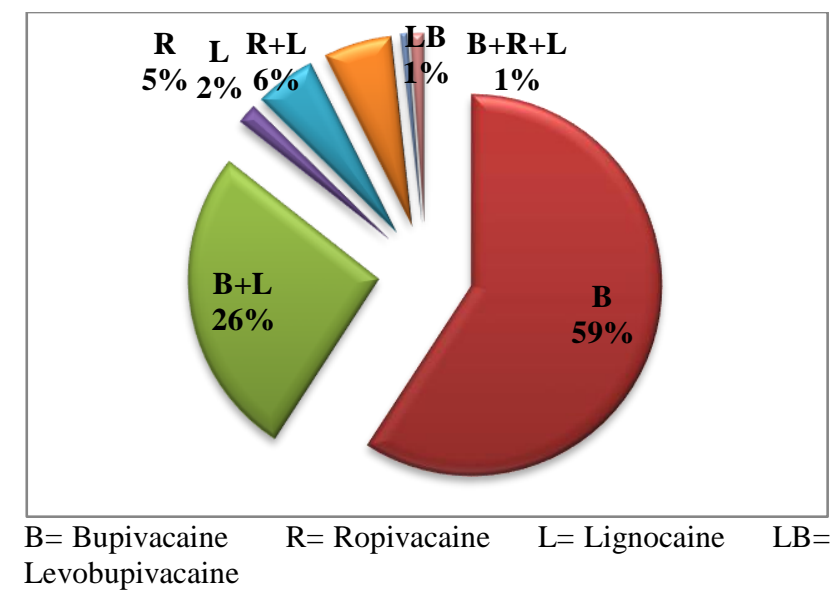

Figure 3: Percentage of choice of anesthetic agents used.

Bupivacaine (B) is the most commonly used single local anesthetic agent here and the most common dose range of Bupivacaine $(0.5 \%)$ is $3-4 \mathrm{ml}(58.25 \%)$.

Out of total 348 cases undergoing anesthesia using local anesthetic agents, 228 cases required only a single agent and 120 cases required a combination anesthetic agents. Among 228 cases requiring single agent, 206 underwent sub-arachnoid block (SAB), 16 epidural block (EPID) and only 2 brachial block and out of 120 cases requiring a combination of agents, 56 underwent sub-arachnoid block, 32 brachial block, 16 epidural block. The test of association between the no.of agents used and the type of anesthetic procedure performed was significantly associated. $(\mathrm{P}<0.05)$ (Table 1$)$.

Table 1: No. of agents used vs anesthetic procedure.

\begin{tabular}{|llllll|}
\hline No. of agents & BB & EPID & SAB & Others & Total \\
\hline Combination & 36 & 16 & 56 & 12 & 120 \\
\hline Single & 2 & 16 & 206 & 4 & 228 \\
\hline Total & 38 & 32 & 262 & 16 & 348 \\
\hline
\end{tabular}

$\mathrm{X} 2=56.442, \mathrm{P}<0.05$

Table 2: Anesthetic procedures performed in each department.

\begin{tabular}{|llll|ll|}
\hline Department & BB & EPID & SAB & Others & Total \\
\hline OBG & 0 & 6 & 122 & 2 & 132 \\
\hline ORTHO & 34 & 20 & 24 & 12 & 88 \\
\hline SURG & 4 & 6 & 116 & 2 & 128 \\
\hline Total & 38 & 32 & 262 & 16 & 348 \\
\hline
\end{tabular}

$\mathrm{X} 2=123.575, \mathrm{P}<0.05$

Out of 262 patients undergoing Sub-arachnoid block, 122 were from department of Obstetrics and Gynaecology, 116 from General Surgery and 24 from Orthopaedics. Among 38 Brachial block cases 34 were from department of Orthopaedics, only 4 from General surgery and 2 from Obstetrics and Gynaecology. Of 32 epidural cases 20 were from department of Obstetrics and Gynaecology, 6 from General surgery and 6 from Orthopaedics. The test of association between the department concerned and the type of anaesthetic procedure performed was significantly associated. $(\mathrm{P}<0.05)$ (Table 2$)$.

Out of 348 cases collected only 40 cases have reported complications or adverse effects among which hypotension was most common $(45 \%)$ followed by both hypotension and bradycardia (25\%). This is shown as percentage in Figure 4.

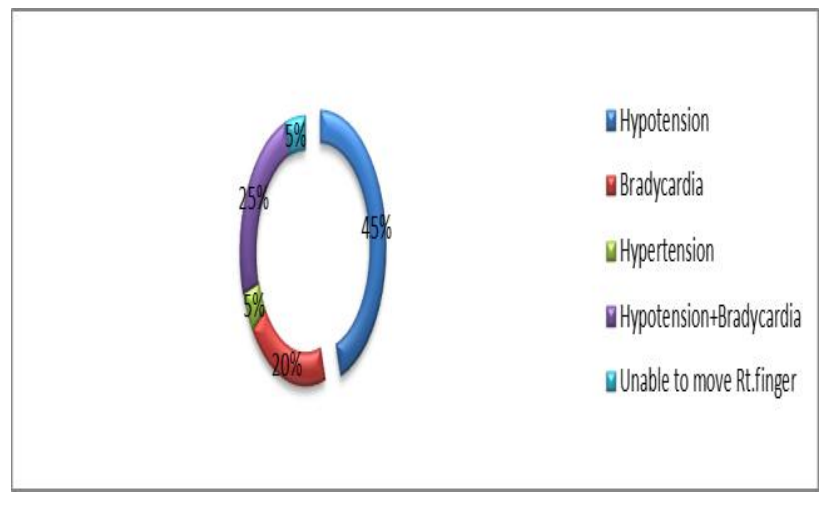

Figure 4: Percentage of complications during anesthesia.

In 182 cases adjuvants were used out of total 348 cases. Figure 5 shows the number of times Adjuvant drugs used along with Local anesthetics where Ephedrine (30.48\%) followed by Opioid analgesics (24.39\%) were more commonly used.

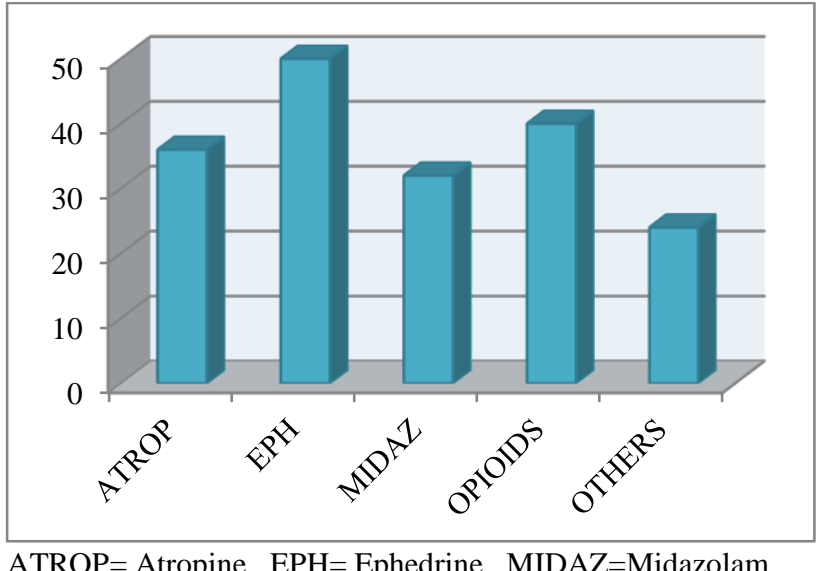

Figure 5: Adjuvants used with local anaesthetics.

\section{Results of general anaesthetic agents}

Next we depict the results of use of general anesthetic agents. A total of 574 cases were collected and screened according to inclusion and exclusion criteria and finally 236 cases were recorded and critically analysed.

The mean age of patients undergoing various surgeries using local anesthetic agents is $36.92 \pm 1.36$. 
The female patients $(59 \%)$ are more than male patients (41\%) undergoing various surgeries using general anesthetic agents.

Figure 6 shows the Percentage of operative procedures performed under general anaesthesia using general anaesthetic agents. Ear Nose and Throat (ENT) department leads the group (48\%) followed by General Surgery (SURG) (31\%), Obtetrics and Gynaecology $(\mathrm{OBG})(18 \%)$ and least in Orthopaedics (ORTHO) (3\%).

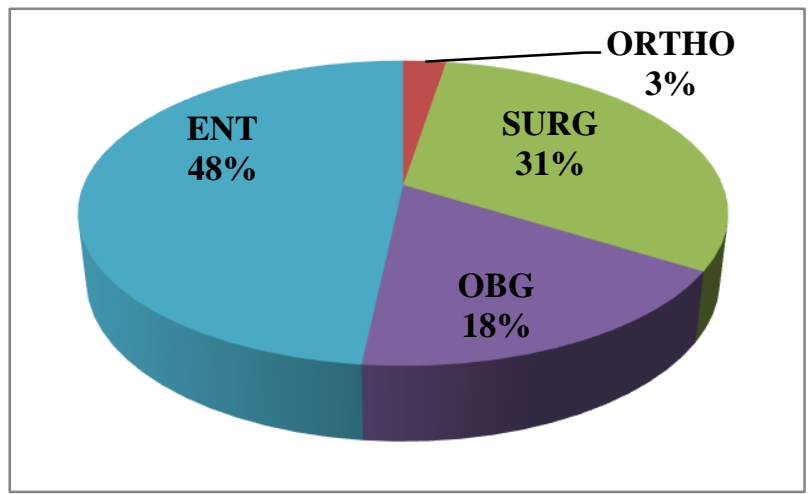

Figure 6: Percentage of cases according to departments.

In this study we have seen that in only $3 \%$ of cases a combination of two anesthetic agents are used for induction of general anesthesia whereas in $97 \%$ of cases a single agent is used for induction. The mean no. of anesthetic agents used for induction of general anaesthesia for the operative procedures performed by the respective departments (OBG, SURG, ENT and ORTHO) are represented in Table 3.

Table 3: Mean no. of inducing anesthetic agents used per department.

\begin{tabular}{|l|l|l|}
\hline Department & Mean & St. Err \\
\hline ENT & 1.025 & 0.014 \\
\hline OBG & 1.044 & 0.025 \\
\hline ORTHO & 1.045 & 0.025 \\
\hline SURG & 1.034 & 0.019 \\
\hline
\end{tabular}

The most preferred choice of agents used for induction of general anesthesia is Thiopentone $(86 \%)$ followed by Propofol (10\%). Ketamine $(1 \%)$ and combination of Thiopentone and Propofol (3\%) were rarely used.

The dose range of Thiopentone most commonly employed for induction of general anaesthesia was 200$299 \mathrm{mg}$ followed by $300-399 \mathrm{mg}$. We have found that the most commonly used agent for maintainence of general anesthesia is Isoflurane (68\%) followed by Halothane $(32 \%)$.

In most of the cases undergoing general anesthesia, skeletal muscle relaxation was required either by single
(19\%) or combination (77\%) of agents. Only $4 \%$ of cases did not require skeletal muscle relaxation.

The most commonly used combination of skeletal muscle relaxants were Succinylcholine $(\mathrm{SCH})$ with either Atracurium (ATR) (39.8\%) or Vecuronium (VEC) $(37.16 \%)$ (Figure 7).

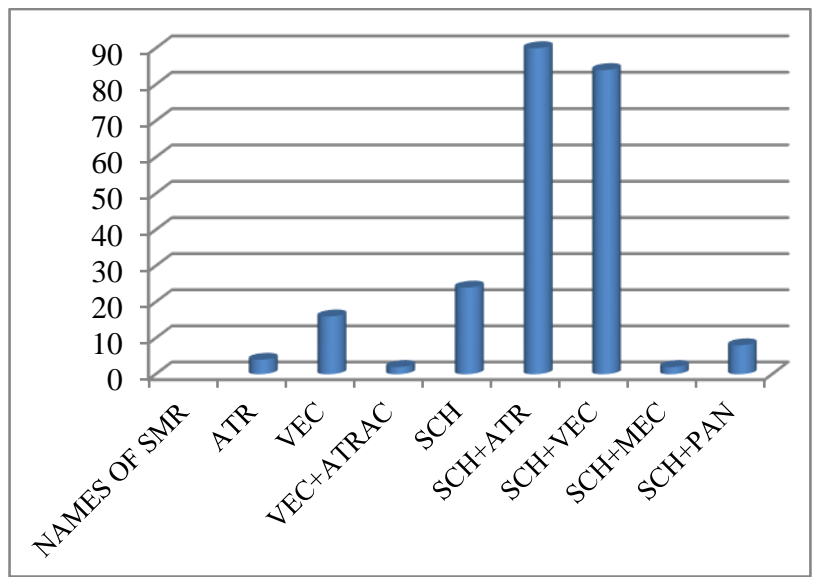

$\mathrm{SMR}=$ Skeletal Muscle Relaxants, ATR $=$ Atracurium

$\mathrm{VEC}=$ Vecuronium, $\mathrm{SCH}=$ Succinylcholine

$\mathrm{MEC}=$ Mecuronium, $\mathrm{PAN}=$ Pancuronium

\section{Figure 7: Types of skeletal muscle relaxants used.}

Out of 236 cases only 41 cases were reported with complications pertaining to general anaesthesia. Postoperative pain (49\%) and vomiting (29\%) were the most common followed by few cases of anaphylaxis (10\%) hypotension (5\%) and hypertension (7\%) (Figure 8 ).

Among 236 total cases only in 86 cases adjuvants were used. Analgesics (both opioids and NSAIDs) were the most commonly used adjuvants followed by ondansetron.

Out of 236 cases undergoing anaesthesia using general anaesthetic agents, 160 cases required isoflurane and 76 cases required halothane as the inhalational agent for maintenance of general anaesthetic state.

Among 160 cases requiring Isoflurane, 50 underwent GI (Gastro-intestinal) surgery, 30 underwent pelvic surgery and 80 head-neck surgery and among 76 cases requiring halothane 26 underwnt GI surgery, 12 underwent Pelvic surgery, 32 underwent head-neck surgery and 6 underwent Orthopaedic (Ortho) surgery.

The test of association between the type of inhalational agent used and the nature of surgey was found not significant. $(\mathrm{P}>0.05)$ (Table 4$)$.

Out of 204 cases receiving thiopentone as the i.e. inducing agent, 36 were below 25 yrs age, 126 were within age group 26-50 yrs and 42 were within age group 51-75 yrs. Among 36 cases below 25 yrs age group, 22 received thiopentone at the dose range of $50-150 \mathrm{mg}, 14$ received at the dose range of $151-300 \mathrm{mg}$ and among 126 
cases within age group 26-50 yrs, all of them received at the dose range of $151-300 \mathrm{mg}$ and among 42 cases within 51-75 yrs age group, 25 received at the dose range of $301-450 \mathrm{mg}$ and 17 received at the dose range of 151-300 $\mathrm{mg}$. The test of association between the age of patient and the dose of thiopentone received was found to be significant $(\mathrm{P}<0.05)$ (Table 5).

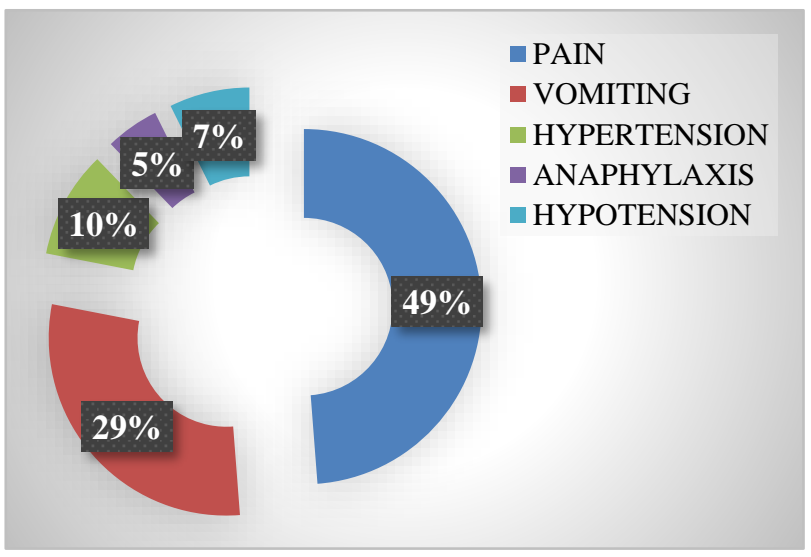

Figure 8: Percentage of complications pertaining to general anesthesia.

Table 4: Type of inhalational (Inh) agent Vs. nature of surgery.

\begin{tabular}{|llll|ll|}
\hline \multicolumn{7}{|l|}{ Nature of surgery } \\
\hline $\begin{array}{l}\text { Inh. } \\
\text { agent }\end{array}$ & $\begin{array}{l}\text { GI } \\
\text { Surg }\end{array}$ & Pelvic & Head/neck & Ortho & Total \\
\hline ISO & $\begin{array}{l}50 \\
(31 \%)\end{array}$ & $\begin{array}{l}30 \\
(19 \%)\end{array}$ & $80(50 \%)$ & 0 & 160 \\
\hline HALO & $\begin{array}{l}26 \\
(34 \%)\end{array}$ & $\begin{array}{l}12 \\
(16 \%)\end{array}$ & $32(42 \%)$ & $\begin{array}{l}6 \\
(8 \%)\end{array}$ & 76 \\
\hline Total & 76 & 42 & 112 & 6 & 236 \\
\hline
\end{tabular}

Cont. Coeff. $=0.234, \mathrm{X}^{2}=6.851, \mathrm{P}>0.05$

Table 5: Age of patients (in yrs) Vs. dose of thiopentone (in $\mathrm{mg}$ ).

\begin{tabular}{|lllll|}
\hline \multicolumn{5}{|c|}{ Dose of Thiopentone (in mg) } \\
\hline Age $(\mathbf{y r s})$ & $\mathbf{5 0 - 1 5 0}$ & $\mathbf{1 5 1 - 3 0 0}$ & $\mathbf{3 0 1 - 4 5 0}$ & Total \\
\hline$<25$ & 22 & 14 & 0 & 36 \\
\hline $26-50$ & 0 & 126 & 0 & 126 \\
\hline $51-75$ & 0 & 17 & 25 & 42 \\
\hline Total & 22 & 157 & 25 & 204 \\
\hline
\end{tabular}

Cont. Coeff. $=0.734, \mathrm{X}^{2}=137.588, \mathrm{P}<0.05$

Out of total 236 cases receiving Succinylcholine (Sch) as skeletal muscle relaxant 50 cases were under 25 yrs of age, 140 were within the age group 26-50 yrs and 46 were above 51-75 yrs age group. Among 50 cases under 25 yrs age, all case $(100 \%)$ received Sch at a dose range below $50 \mathrm{mg}$. Among 140 cases in the age group 26-50, $136(97 \%)$ received Sch at the dose range of 51-100mg and only $4(3 \%)$ received below $50 \mathrm{mg}$. Among 46 cases within age group 51-75 yrs, $28(61 \%)$ received Sch at the dose range above $100 \mathrm{mg}$ and $18(39 \%)$ received within dose range of 51-100 mg. Hence it was found that the test of association between the age of patient and the dose of $\mathrm{Sch}$ received was significant $(\mathrm{P}<0.05)$.

\section{DISCUSSION}

This study dwells on the current trends and practices of local anesthetic agents in various surgical procedures at a rural teaching hospital. It was conducted at the Anesthesia department of K.V.G. Medical college, Sullia over a period of 6 months (December 2014 - May 2015) which includes 1 month of pilot study.

In this study, a total of 174 cases were screened and analysed. It was found that Male (46\%) and Female (54\%) patients underwent almost equal number of surgeries. Hence the Gender prevalence has not much significance related to the use of anesthetic agents.

It also depicts that almost equal no. of surgeries are performed in OBG (35\%), Orthopaedics (32\%) and General Surgery (33\%) departments using local anesthetic agents.

It also shows that average no. of Anesthetic agents used per Operative procedure is same (1.26) for all departments, hence the type of operative procedure does not influence the no. of agents.

The study shows that the most common anesthetic procedure performed using local anesthetic agents is Spinal anesthesia /Sub-arachnoid block (SAB) (75.28\%) as most of the lower abdominal surgeries performed in this hospital like LSCS, Inguinal hernia repair , appendicectomy, hysterectomies are done under Spinal anesthesia which is in accordance to the standard guidelines of ASA thoughaccording to ASA combined spinal-epidural anesthesia (CSEA) can also be employed. ${ }^{14}$ In another study done by Corning JL et.al he states that Subarachnoid (spinal) block is a safe and effective alternative to general anesthesia when the surgical site is located on the lower extremities, perineum (eg, surgery on the genitalia or anus), or lower body wall (eg, inguinal herniorrhaphy). Cesarean deliveries are routinely performed under spinal anesthesia, as are total hip arthroplasty and total knee arthroplasty.,15

In this study, we have found that Bupivacaine (B) is the most commonly used local anesthetic agent (59\%) followed by combination of bupivacaine (B) and lignocaine (L) (26\%) which is quite similar to a study done in U.S. by Concepcion MA where Lidocaine, tetracaine, and bupivacaine are the local anesthetic agents most commonly employed for spinal anesthesia. ${ }^{8}$

We have also seen that bupivacaine $(0.5 \%)$ which is the most commonly employed local anesthetic agent is given by SAB mostly at the dose range of 3-4 ml followed by 2-3 $\mathrm{ml}$. It is given at 3-3.5 $\mathrm{ml}$ for most cases of lower gastrointestinal surgeries. (e.g. appendicectomy, 
herniarepair, hysterectomies etc.) and at 3.5-4 $\mathrm{ml}$ for orthopaedic surgeries (e.g. Amputations, arthroscopy, hemiarthroplasty etc.) or some longer duration procedures and at the dose of $2-2.5 \mathrm{ml}$ for caesarean sections. Lower doses $(<2 \mathrm{ml})$ are used for minor surgeries like circumcision, orchidectomy, anal surgeries, excisions etc.

For epidural block Bupivacaine is used at higher doses $(8-16 \mathrm{ml})$. Though ropivacaine is less cardiotoxic than bupivacaine it is seldomly used for regional anesthesia.

Brachial block, axillary block and other conduction blocks are used for orthopaedic surgeries involving upper limb like nerve repair, wound debridement, reduction of various fractures.

There was significant association found $(\mathrm{P}<0.05)$ between the type of anesthetic procedure performed and whether single or combination of anesthetic agents used. In most of the cases Suba-arachnoid block was performed using Bupivacaine $(0.5 \%)$.

There was also significant association found $(\mathrm{P}<0.05)$ between the various departments concerned and the type of anesthetic procedure performed. Sub-arachnoid block was mostly performed except in Orthopaedics operative procedures invoving upper limb where brachial block was more preferred and in few cases of OBG like Total laparoscopic Hysterectomies where Epidural block was employed alongwith general anesthesia.

There were only 20 cases reported with complications pertaining to Spinal anesthesia which was just $11.49 \%$ of total cases among which hypotension (45\%) and bradycardia $(20 \%)$ were quite frequent.

In a similar prospective study at Finland on complications of spinal anesthesia done by Tarkkila PJ it was found that in 1881 patients $26 \%$ of them suffered from one or more complications. The most common complications were hypotension $(16.4 \%)$ and bradycardia $(8.9 \%) .{ }^{16}$

We have also found that certain adjuvants are used along with local anesthetics among which most frequently ephedrine, atropine and opiodanalgesics were mainly employed for prevention or treatment of common complications like hypotension, bradycardia and pain at injection site and relieve of anxiety and apprehension of a surgery.

Hence Regional anesthesia is safe, provided that the anaesthetist is aware of the complications associated with the various techniques, takes precautions to prevent complications where possible, carefully monitors the patient, and treats complications timeously and appropriately. ${ }^{17}$

\section{CONCLUSION}

This study showed that the most common anesthetic procedure performed using local anesthetic agents is Spinal anesthesia /Sub-arachnoid block (SAB) and the most common agent used is bupivacaine which was frequently employed at the dose range of 3-4 ml. There was significant association found between the no. of anesthetic agents used and the type of anesthetic procedure performed and also between the concerned department and the type of anesthetic procedure performed.

Thus, the rationality in the usage of relevant anesthetic agents with appropriate adjuvants is evident.

The choice of anaesthetic agent for surgical procedure was strongly associated with the technique they used for the induction and, it is bupivacaine which was used for $\mathrm{SAB}$ in majority. The utmost use of single anaesthetic agent with adjuvants sufficed the procedures in majority rather than use of combinations.

Funding: No funding sources

Conflict of interest: None declared

Ethical approval: The study was approved by the Institutional Ethics Committee

\section{REFERENCES}

1. Katzung BG, Masters SB, Trevor AJ. General anesthetics. In: Basic and clinical pharmacology. $11^{\text {th }}$ Ed. NewYork: McGraw Hill; 2009:423.

2. Brunton LL, Chabner BA, Knollman BC. General anesthetics and therapeutic gases. In: Goodman \& Gillman's The Pharmacological Basis of Therapeutics. 12 ${ }^{\text {th }}$ Ed. New York: McGraw Hill; 2011:527-582.

3. Covino BG, Giddon DB. Pharmacology of local anesthetic agents. J Dent Res. 1981 Aug;60(8):14549.

4. Scott DB, Jebson PJ, Braid DP, Ortengren B, Frisch P. Factors affecting plasma levels of lignocaine and prilocaine. British Journal of Anaesthesia. 1972 Oct 1;44(10):1040-9.

5. Becker DE, Reed KL. Essentials of Local Anesthetic Pharmacology. Anesth Prog. 2006;53(3):98-109.

6. Barash, Paul G, Cullen, Bruce F, Stoelting, Robert K. Clinical Anesthesia. $4^{\text {th }}$ Ed. Philadelphia: Lippincott Williams \& Wilkins; 2001.

7. Corning JL. Spinal anesthesia and local medications of the cord. NewYork Med J. 1885;42:483.

8. Concepcion MA. Spinal anesthetic agents. International anesthesiology clinics. 1989 Apr $1 ; 27(1): 21-5$.

9. MIMS Online. Bupivacaine Hydrochloride (Internet). [cited 2007 September 26]. Available at: http://mims.hcn.net.au.ezproxy.library.uwa.edu.au 
10. MIMS Online. Ropivacaine Hydrochloride (Internet). [cited 2007 September 26]. Available at: http://mims.hen.net.au.ezproxy.library.uwa.edu.au

11. Rull G. Action against Medical Accidents (Internet). [updated on 2010 May 21; cited on 2013 Oct 31]. Available at:

http://www.patient.co.uk/doctor/importantcomplications-of-anaesthesia

12. Hyderally H. Complications of spinal anesthesia. Mt Sinai J Med. 2002 Jan-Mar;69(1-2):55-6.

13. Carpenter RL, Caplan RA, Brown DL, Stephenson C, $\mathrm{Wu} \mathrm{R}$. Incidence and risk factors for side effects of spinal anesthesia. Anesthesiology. Jun 1992;76(6):906-16.

14. The American Society of Anesthesiologists. Practice Guidelines for Obstetric Anesthesia. Anesthesiology. 2007; 106:843-63.

15. Braga Ade F, Frias JA, Braga FS, Pereira RI, Titotto SM. Spinal anesthesia for elective ceasarean section: use of different doses of hyperbaric bupivacaine associated with morphine and clonidine. Acta Cir Bras. 2013 Jan;28(1):26-32.

16. Tarkkila PJ, Kaukinen S. Complications during spinal anesthesia: a prospective study. Reg Anesth. 1991 Mar-Apr;16(2):101-6.

17. Lamacraft G. Complications associated with regional anaesthesia for Caesarean section. Southern African Journal of Anaesthesia and Analgesia. 2004 Oct;10(1):15-20.

Cite this article as: Ganguly D, Ranganath DD, Herle M, Rajasekhar CH, Nagaraj KB. A prospective study on the use of anesthetic agents in modern surgical practice at a tertiary care hospital, Karnataka, India. Int J Basic Clin Pharmacol 2017;6:1612-9. 